IZA DP No. 9258

New Evidence on Mobility and Wages

of the Young and the Old

Jorgen Hansen

Damba Lkhagvasuren

August 2015

Forschungsinstitut

zur Zukunft der Arbeit

Institute for the Study

of Labor 


\title{
New Evidence on Mobility and Wages of the Young and the Old
}

\author{
Jorgen Hansen \\ Concordia University, \\ CIRANO, CIREQ and IZA \\ Damba Lkhagvasuren \\ Concordia University, \\ National University of Mongolia and CIREQ
}

Discussion Paper No. 9258

August 2015

\author{
IZA \\ P.O. Box 7240 \\ 53072 Bonn \\ Germany \\ Phone: +49-228-3894-0 \\ Fax: +49-228-3894-180 \\ E-mail: iza@iza.org
}

Any opinions expressed here are those of the author(s) and not those of IZA. Research published in this series may include views on policy, but the institute itself takes no institutional policy positions. The IZA research network is committed to the IZA Guiding Principles of Research Integrity.

The Institute for the Study of Labor (IZA) in Bonn is a local and virtual international research center and a place of communication between science, politics and business. IZA is an independent nonprofit organization supported by Deutsche Post Foundation. The center is associated with the University of Bonn and offers a stimulating research environment through its international network, workshops and conferences, data service, project support, research visits and doctoral program. IZA engages in (i) original and internationally competitive research in all fields of labor economics, (ii) development of policy concepts, and (iii) dissemination of research results and concepts to the interested public.

IZA Discussion Papers often represent preliminary work and are circulated to encourage discussion. Citation of such a paper should account for its provisional character. A revised version may be available directly from the author. 
IZA Discussion Paper No. 9258

August 2015

\section{ABSTRACT}

\section{New Evidence on Mobility and Wages of the Young and the Old}

We present new evidence on the wage and mobility of young and old workers, which is difficult to explain using standard human capital theory. Instead, we propose a simple dynamic extension of the Roy model, where worker migration and wages are jointly determined at the individual level. According to this model, a higher moving cost among older workers is the main factor driving the lower mobility among this group. Because of the higher moving costs, older workers require a higher wage increase to move across regions than younger workers, a pattern that is consistent with individual-level U.S. data. We also find an interesting dynamic effect suggesting that, given a persistent labor income shock, a higher future moving cost makes workers more mobile today.

JEL Classification: E24, J31, J61, R23

Keywords: geographic mobility, labor mobility by age, labor income shock, moving cost, multi-sector model

Corresponding author:

Jorgen Hansen

Department of Economics

Concordia University

1455 de Maisonneuve Blvd. West

Montreal, Quebec, H3G 1M8

Canada

E-mail: jorgen.hansen@concordia.ca

\footnotetext{
* We received helpful comments from Árpád Ábrahám, Mark Bils, Gordon Dahl, Uta Schönberg, Jonathan Heathcote, Lutz Hendricks, John Kennan, Seik Kim, Ronni Pavan, Stephen Ross, Christopher Taber, and the participants at various seminars and conferences. Damba Lkhagvasuren gratefully acknowledge financial support from FRQSC grant 2014-NP-174520. All remaining errors are ours.
} 


\section{Introduction}

It is well known that geographic mobility is lower among older workers. For example, according to the U.S. census, workers who are between 30 and 44 years of age are more than twice as mobile as workers who are between 44 and 59 (see Table 1 and Greenwood, 1997). While there is a growing literature that uses a behavioral model of worker migration and wages to analyze the process through which the labor force is reallocated across local markets ${ }^{1}$ it is fair to say that most of the quantitative studies focus on either young or ex-ante identical workers.

While there is some limited evidence on the aggregate effect of labor mobility of different age and educational groups (e.g., Topel, 1986), the literature has devoted little attention to the individual-level relationship between mobility and earnings of different demographic groups. In fact, using the U.S. census data, we show that the relationship between mobility and wages exhibits strikingly different patterns across age and educational groups. This paper aims to provide a dynamic, quantitative model that can account for the key features of mobility and wages of different age and educational groups. In the absence of such a model, it seems difficult to have a consistent description of labor income.

We show that the combination of direct moving costs and location-specific labor income shocks accounts for key features of U.S. data on migration, including new facts on the mover-stayer wage gap. Although we focus on the age gap of mobility, we need to allow for educational differences for the following two considerations. First, geographic mobility is much higher among the more educated (e.g., Machin, Pelko-

\footnotetext{
${ }^{1}$ For example, Coen-Pirani (2010) analyzes inter-state labor flows and state-level wages while extending Lucas and Prescott (1974) to allow for both net and gross mobility. Kennan and Walker (2011) analyze the geographic mobility patterns of young high school graduates while focusing on their repeat mobility. Using a multi-location model of labor migration and firm-worker trading frictions, Lkhagvasuren (2012) analyzes unemployment differences between U.S. states. Bayer and Juessen (2012) analyzes the dynamic selection issues associated with individuals' locational choices and show that ignoring the persistence of location-specific labor income shocks leads to a large upward bias in estimated moving costs.
} 
nen and Salvanes, 2012, and Malamud and Wozniak, 2012). Second, the individuallevel relationship between wage and mobility is markedly different across educational groups. For example, among high-school-educated workers, in-migrants earn less than the incumbent workers, whereas among college-educated workers, the opposite is true (Lkhagvasuren, 2014). ${ }^{2}$ Therefore, and given that wages and mobility are jointly determined, one has to allow for educational differences when modelling these outcomes.

We make three main contributions to the literature. First, we document that although the share of net mobility in overall mobility is relatively small, it varies across age groups with higher shares for older workers. As in Davis and Haltiwanger (1992), net mobility refers to the part of the worker flows that accounts for the observed net migration across regions, while excess mobility is defined as overall mobility minus net mobility. This age gap in the share of net mobility represents another important difference in regional mobility between young and old workers.

Secondly, we also show how the wage gap between in-migrants (movers) and incumbents (stayers) depends on age. According to data from the U.S. census for the years 1980-2000, the negative mover-stayer wage gap of high school graduates is smaller among older workers, while the positive mover-stayer wage gap of college-educated workers is greater among older workers.

Finally, we show how these unique patterns of mobility and wages for different age and educational groups can arise from a simple quantitative model. Following the long tradition in the literature on self-selection and earnings, we build on Roy's (1951) model of sectoral choice. ${ }^{3}$ The key feature of the Roy (1951) model that is important for our analysis is that labor mobility is directed in the sense that workers know their

\footnotetext{
${ }^{2}$ Earlier work on migration and wages find only a negative wage gap between movers and stayers (e.g., Grant and Vanderkamp, 1980, Borjas, Bronars and Trejo, 1992a, and Krieg, 1997). As shown in Lkhagvasuren (2014), this is because earlier studies maintain a strong assumption that the wagemobility relationship is the same across demographic groups.

${ }^{3}$ See Heckman and Taber (2008) for the recent survey of applications of the Roy (1951) model, especially in contexts relating earnings to a sectoral selection. Borjas, Bronars and Trejo (1992b) and Dahl (2002) extend the model's application to internal migration.
} 
wage at the destination. ${ }^{4}$ We extend the model to a stochastic, dynamic setting with different age groups. Workers move across regions at a cost that is allowed to differ across age and educational groups. We distinguish between three key components of individuals' labor income: unobserved ability, an idiosyncratic labor income shock and a regional-level shock.

By introducing both an idiosyncratic labor income shock that is specific to the worker-location match and a regional level shock, that is common to local workers, we are able to generate simultaneous in- and out-migration while also creating net mobility at the regional level. Thus, in contrast to the multi-sector model with different demographic groups considered by Topel (1986), which focuses only on net migration, the model considered in this paper allows for both net and excess labor flows. ${ }^{5}$ In addition to creating excess labor flows, the idiosyncratic shocks also contribute to the wage gap between movers and stayers.

We calibrate the model to the new facts documented in the paper. Specifically, in addition to overall mobility and the mover-stayer wage gap, we use the relative magnitude of net versus gross mobility to discipline the model. According to the model, the moving cost increases with age. Because of their higher moving cost, older workers move only when they have a much better wage draw at the destination. Therefore, the selection effect along the idiosyncratic income shock is higher among older workers while making the wage of older movers larger relative to that of younger movers. More importantly, counterfactual experiments show that a higher moving cost among older workers explain two thirds of the mobility gap between young and old workers. The model is also able to generate a higher regional variation in mobility of older workers.

It should be stressed that earlier work on internal migration (e.g., Grant and Van-

\footnotetext{
${ }^{4}$ In the commonly used model of sectoral dynamics by Lucas and Prescott (1974), mobility is undirected and workers move across sectors without knowing their destination wages. That type of undirected mobility is not suitable for analyzing the individual-level relationship between wages and mobility.

${ }^{5}$ Moscarini (2001) considers a similar model of excess mobility.
} 
derkamp, 1980 and Borjas et al., 1992a) find only a negative wage gap between movers and stayers. ${ }^{6}$ These studies also find a positive relationship between the wage of in-migrants in their new location and the length of time that has elapsed since inmigration. These facts support the view that human capital is location-specific (e.g., Borjas et al., $1992 a$ and Krieg, 1997). While location-specific human capital might be essential for the wage growth, it alone cannot explain the wage level of movers. For instance, under this view, local residents earn more than new in-migrants. Moreover, since older workers have more location-specific skills relative to younger workers, older movers perform worse than younger movers when compared with local residents. These predictions are inconsistent with the positive mover-stayer wage gap among college educated workers, and the fact that, within each educational group, older movers tend to perform better than the younger movers at their destination. The current paper focuses on the wage level of in-migrants and thus can be viewed as complementary to the previous empirical studies on the wage growth of in-migrants. At the same time, it should be noted that the model generates a positive correlation between locational tenure and wages using the higher mobility rate among lower ability workers.

The outline of the rest of the paper is as follows. Section 2 presents the main empirical findings on the relationship between mobility and wages. Section 3 extends Roy's (1951) model to a dynamic stochastic setting with costly mobility. Section 4 solves the model and presents the main results. Section 5 considers counterfactual numerical experiments. Section 6 draws together the conclusions of the paper.

\section{Facts}

This section presents key empirical findings using U.S. census data. First, it measures mobility among different age groups and shows that both the level and regional variation of mobility differ considerably among age groups. Second, it shows that the

\footnotetext{
${ }^{6}$ See Section 2 for the reason behind the difference between the results in the earlier work and those in the current paper.
} 
relationship between mobility and wages exhibits strikingly different patterns across age and educational groups. As in Coen-Pirani (2010) and Lkhagvasuren (2014), to limit the impact of schooling and retirement, we consider workers aged 30 to 59. We categorize workers between 30 and 44 as young, while those between 45 and 59 are classified as old. We restrict our sample to white male employees who are not in the armed forces and who worked between 20 and 80 hours per week for at least 17 weeks during the year. We exclude self-employed and unpaid family workers as well as those who attend school.

Given the data limitations explained in Appendix, the main geographic units considered in the empirical analysis are the census divisions. For brevity, census divisions will be referred to as regions for the remainder of the paper. Experimentation shows that when using census divisions, reducing the initial sample size by 2-5 times by random sampling does not have much effect on the measured moments. This means that, in the U.S. census data, defining regions as census divisions works well for our purpose. According to Blanchard and Katz (1992), the census divisions are relatively homogeneous and thus provide a natural way to pool U.S. states.

It should be made clear that it is very difficult, if not impossible, to retrieve the pattern of the mover-stayer wage gap from commonly used panel data sets such as the National Longitudinal Survey of Youth and the Panel Study of Income Dynamics. The main reason is that the sample sizes of these surveys are too small to measure not only the mean wage of movers but also the average wage of local residents. Specifically, these data sets survey a few thousand individuals and thus the total number of movers within a location for a given year is very small, which makes it very hard to construct a reliable measure of the effect of mobility on wages by age and education while controlling for the location effects. 


\subsection{The share of net mobility}

The U.S. census records respondents' current state of residence and the state in which they resided five years ago. Therefore, an individual's mobility status is obtained for a five-year interval. The upper panel of Table 1 displays the economy-wide gross mobility rate. It shows that younger workers are about twice as mobile as older workers.

Next we measure how mobility at the regional level differ across age groups. For this purpose, we measure net mobility as follows. Let $m_{j, t}^{\text {in }}$ and $m_{j, t}^{\text {out }}$ denote the inand out-migration rates for region $j$. As in Davis and Haltiwanger (1992), overall net

mobility $\delta$ is given by the average of $\left|m_{j, t}^{\text {in }}-m_{j, t}^{\text {out }}\right| / 2$ across locations (i.e., across $j$ s). The lower panel of Table 1 shows that net mobility denoted by $\delta$ constitutes a small fraction of overall mobility for each group and therefore much smaller than the age gap in mobility. Consequently, the share of net mobility, labeled as $v$ (i.e., $v=\delta / m$ ), increases with age. This new fact represents another important dimension of mobility differences among the young and the old. It should be noted that net migration across regions constitutes only 10-20\% percent of mobility and therefore cannot alone account for the large mobility differences that we observe across age groups. It is important to keep this in mind when constructing the model in the next section.

\subsection{Wage gap between movers and stayers}

Next we show that there is a substantial wage gap between movers and stayers and that this wage gap exhibits patterns that are difficult to explain using standard human capital theory with location-specific tenure. 
Table 1: Mobility by Age and Education

\begin{tabular}{lcc}
\hline & $\begin{array}{c}\text { young } \\
30-44\end{array}$ yrs. & old \\
& $45-59$ yrs. \\
\hline $\begin{array}{l}\text { Gross mobility, } m \\
\text { high school }\end{array}$ & 0.053 & 0.029 \\
& $(933,484)$ & $(636,459)$ \\
$\quad$ college & 0.113 & 0.059 \\
& $(509,297)$ & $(316,949)$ \\
Net mobility across regions, $\delta$ & & \\
$\quad$ high school & 0.008 & 0.007 \\
$\quad$ college & 0.013 & 0.010 \\
Share of net mobility, $v=\delta / m \times 100 \%$ & & \\
$\quad$ high school & $15 \%$ & $24 \%$ \\
$\quad$ college & $12 \%$ & $17 \%$ \\
\end{tabular}

Notes: This table shows labor mobility across census divisions at a quinquennial frequency. The mobility rates are calculated using Integrated Public Use Micro Samples of the Census 1980-2000 (Ruggles et al., 2010). For the sample selection criteria, see Section 2. The column denoted by young refers to those between 30 and 44 years of age, while the column labeled old is for those who are between 45 and 59 years of age. The labels high school and college denote, respectively, 12 years of education and a bachelor's degree as defined by Ruggles et al., 2010. The number of observations are in parenthesis. 


\section{Level differences}

Let $w_{i, t, j}^{s}$ denote the hourly wage of person $i$ with education level $s$ in location $j$ in year t. Consider the following regression:

$$
\log \left(w_{i, t, j}^{s}\right)=\gamma d_{i, t, j}^{s}+G^{s}\left(a_{i}\right)+\alpha_{t}^{s}+\alpha_{j}^{s}+\epsilon_{i, t, j}^{s}
$$

where $d_{i, t, j}^{s}$ is a dummy for whether the person has recently migrated to region $j, G^{s}\left(a_{i}\right)$ is a quartic polynomial of the person's age $a_{i}$, and $\alpha_{t}^{s}$ and $\alpha_{j}^{s}$ denote, respectively, year and region effects. The hourly wage rates are calculated as the ratio of annual labor income to hours worked per year.

Equation (1) is estimated using subsamples of the four main age and educational groups. ${ }^{7}$ The results are shown in Table 2. Depending on age and education, the wage difference between movers and stayers ranges from -10 to 8 percent. To illustrate how large these wage differences are, we compare them with the observed wage gap between high school and college graduated workers. The census data show that the overall wage gap between the two educational groups is 41 percent. Therefore, the range of the mover-stayer wage gap is roughly one half of the college premium, suggesting that the wage gap between movers and stayers is large.

As in Lkhagvasuren (2014), the table shows that the mover-stayer wage gap is negative for high-school-educated workers while it is positive for college-educated workers. More importantly, the results show that the negative mover-stayer wage gap among high school graduates decreases with age, while the positive mover-stayer wage gap among college graduates increases with age.

\footnotetext{
${ }^{7}$ Lkhagvasuren (2014) shows that education-specific age-earnings profiles are important for measuring the effect of mobility on wages. Earlier work on migration and wages find only a negative wage gap between movers and stayers (e.g., Grant and Vanderkamp, 1980, Borjas et al., 1992a, and Krieg, 1997). As shown in Lkhagvasuren (2014), this is because earlier studies maintain a strong assumption that the wage-mobility relationship is the same across demographic groups and thus estimate the above model using the entire sample.
} 
Table 2: Wage Differences Between Movers and Stayers: U.S. Census

\begin{tabular}{|c|c|c|}
\hline & $\begin{array}{c}\text { young } \\
\text { (30-44 yrs.) }\end{array}$ & $\begin{array}{c}\text { old } \\
(45-59 \text { yrs. })\end{array}$ \\
\hline \multicolumn{3}{|c|}{ Level Difference, $\gamma$} \\
\hline high school & $\begin{array}{l}-0.097 \\
(0.003)\end{array}$ & $\begin{array}{l}-0.083 \\
(0.005)\end{array}$ \\
\hline college & $\begin{array}{c}0.051 \\
(0.003)\end{array}$ & $\begin{array}{c}0.081 \\
(0.006)\end{array}$ \\
\hline both & $\begin{array}{l}-0.020 \\
(0.002)\end{array}$ & $\begin{array}{l}-0.001 \\
(0.004)\end{array}$ \\
\hline \multicolumn{3}{|c|}{ Rank Difference, $\tilde{\gamma}$} \\
\hline high school & $\begin{array}{l}-0.063 \\
(0.002)\end{array}$ & $\begin{array}{l}-0.045 \\
(0.003)\end{array}$ \\
\hline college & $\begin{array}{c}0.031 \\
(0.001)\end{array}$ & $\begin{array}{c}0.048 \\
(0.003)\end{array}$ \\
\hline both & $\begin{array}{c}-0.013 \\
(0.001)\end{array}$ & $\begin{array}{c}0.001 \\
(0.002)\end{array}$ \\
\hline
\end{tabular}

Notes: The upper panel, labeled "level difference", summarizes the log wage difference between movers and stayers using the OLS equation (1). The standard errors are in parenthesis. The lower panel summarizes the wage rank difference between movers and stayers measured by equation (3). 


\section{Rank differences}

One can also obtain the above wage patterns without imposing any parametric assumption on the age-earnings profile. Suppose that there are $N_{t, j, a}^{s}$ workers who are $a$ years old and working in location $j$ in year $t$. Let $w_{i, t, j, a}^{s}$ denote the wage of the $i$-th person of these $N_{t, j, a}^{s}$ workers. Consider the following wage rank within each location-age pair:

$$
r_{i, t, j, a}^{s}=\frac{1}{N_{t, j, a}^{s}-1} \sum_{i^{\prime}=1}^{N_{t, j, a}^{s}} \mathcal{I}\left(w_{i, t, j, a}^{s}>w_{i^{\prime}, t, j, a}^{s}\right),
$$

where $\mathcal{I}$ is the indicator function, which takes a value of 1 if its argument is true and 0 otherwise. Note that $r_{i, t, j, a}^{s}$ ranges between 0 and 1, 0 being the rank of the lowest paid worker and 1 the rank of the highest paid worker within each location-age cell. The impact of mobility on the wage rank can be measured using the following simple regression:

$$
r_{i, t, j, a}^{s}=\tilde{\gamma} d_{i, t, j, a}^{s}+\tilde{\alpha}_{t}^{s}+\tilde{\alpha}_{j}^{s}+\tilde{\epsilon}_{i, t, j, a}^{s},
$$

where, as before, $d_{i, t, j, a}^{s}$ is a dummy for whether the person has recently migrated to region $j$, and $\tilde{\alpha}_{t}^{s}$ and $\tilde{\alpha}_{j}^{s}$ are, respectively, the year and location effects. The lower panel of Table 2 displays the measured values of $\tilde{\gamma}$ for different age and educational groups. It shows that the wage rank differences between movers and stayers measured by equation (3) are highly consistent with the wage level differences measured by equation (1).

The main conclusion we draw from these is that when ranked against incumbent workers of the same age and education group, the older workers perform significantly better than younger ones. We will show below that this is consistent with higher moving costs and lower mobility among older workers. 


\section{Model}

As mentioned above, we consider a dynamic extension of Roy's (1951) model. The Roy (1951) model has two key features that are important for our purpose. First, wages and mobility are jointly determined. Secondly, mobility is fully directed in that workers know their initial wage at their destination before leaving their current location. These features are important to capture the individual-level relationship between mobility and wages across different age groups. We present the model for only one educational group while keeping in mind that the parameters are allowed to differ between the groups.

\subsection{Environment}

Consider two regions denoted by -1 and 1 . The regions are populated by a large number of workers. To model individuals' aging process, we adopt overlapping generations with probabilistic aging considered by Gertler (1999). Specifically, workers are either young or old. Let $y$ and $o$ denote these two age levels: $a \in\{y, o\}$. Each period young workers become old with probability $\lambda^{y}$ and old workers leave the labor force with probability $\lambda^{o}$, while new young workers are born to the economy. This modeling choice is made for purely computational reasons. ${ }^{8}$ The main advantage of using probabilistic aging is that it allows one to capture the differences among age groups without substantially increasing the state space in the dynamic programming problem. For more recent models with probabilistic aging similar to that of Gertler (1999), see for example Grafenhofer, Jaag, Keuschnigg and Keuschnigg (2007) and Hock and Weil (2012).

Workers differ by their permanent unobserved ability $\mu$. Let there be two ability levels: $\mu \in\{-s, s\}$, where $s>0$. The cost of moving between the regions can differ by

\footnotetext{
${ }^{8}$ Below in Section 4, we discuss why the numerical solution imposes a very heavy computational demand.
} 
age and ability. Let $C(\mu, a)$ denote the moving cost of a person of ability $\mu \in\{-s, s\}$ and age $a \in\{y, o\}$. Individuals of the same age who have the same ability and reside in the same region still differ because of their location-specific labor income shock. Specifically, each worker's productivity is subject to a stochastic idiosyncratic shock. The magnitude of the shock depends on where the person resides. Let $\left(e_{-1}, e_{1}\right)$ denote these labor income shocks. The pair of shocks is drawn for each person at each period. The stochastic process governing the dynamics of $e_{-1}$ and $e_{1}$ will be introduced shortly.

Labor income of workers in location -1 is subject to a common stochastic shock $z$, which is referred to as a local technology shock. The local technology shock is introduced to only one of the locations. Since there are only two locations and we are focusing on the individual-level wage-mobility relationship, a positive shock in location -1 can be thought of as a negative shock in 1 . The local technology shock $z$ is governed by the following autoregressive process:

$$
z_{t+1}=\varrho z_{t}+\varepsilon_{t},
$$

where $0<\varrho<1$, and $\varepsilon_{t}$ is a zero-mean random variable. Let $\sigma_{z}$ denote the conditional standard deviation of the local technology shock $z_{t}: \sigma_{z}^{2}=\left(1-\varrho^{2}\right) \operatorname{Var}\left(z_{t}\right)$.

Each period consists of four stages shown in Figure 1. In the first stage, individuals observe their labor income shocks $\left(e_{-1}, e_{1}\right)$ along with the local technology shock, $z$. In the second stage, after observing these shocks, individuals choose their location. In the third stage, production takes place and workers are paid their wages. In the last stage, new workers are born to the economy while some of the old workers retire. At the same time, some of the young workers become old. 
Figure 1: Timing of the Events

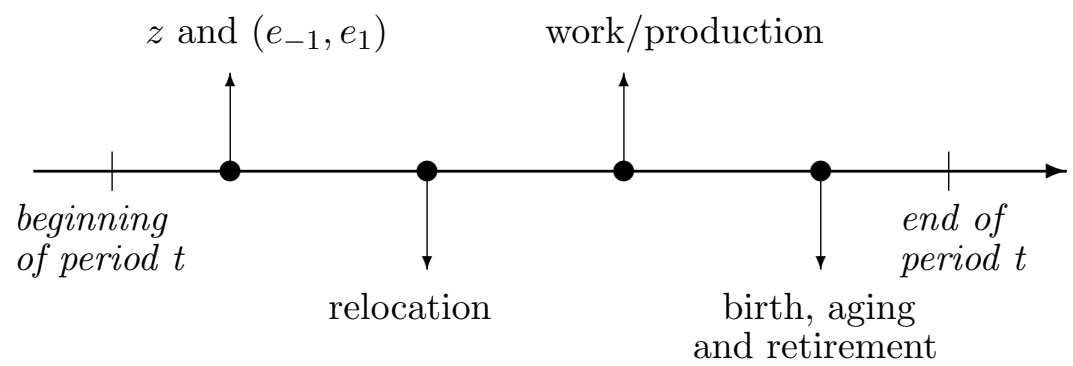

Notes: This figure shows the sequence of the events within each period.

\section{Wages and net income}

Each period a worker is paid his or her marginal product. Depending on whether the person works on location -1 or 1 , the current wage is given by

$$
w_{-1}=\mu+e_{-1}+z
$$

or

$$
w_{1}=\mu+e_{1},
$$

respectively. ${ }^{9}$ Depending on the location, the flow utility of a local resident is given by the log wage in equations (5) and (6). However, the flow utility of an in-migrant moving to location $j$ is $w_{j}-C(\mu, a)$, where $a \in\{y, o\}$ and $j \in\{-1,1\}$.

\section{Shock process}

The labor income or productivity shocks $e_{-1}$ and $e_{1}$ are allowed to be correlated across time and locations. Specifically, they are governed by the following autoregressive

\footnotetext{
${ }^{9}$ Notice that unobserved ability $\mu$ remains constant over time. One can also consider a shock to $\mu$ perhaps by employing a stochastic process that is much more persistent than $e_{-1}$ and $e_{1}$. However, as pointed out by Kennan and Walker (2011), allowing for such income profiles will not affect the results, as long as these profiles are exogenous. It is useful to keep this in mind when interpreting the effect of unobserved ability.
} 
process:

$$
\left\{\begin{array}{l}
e_{-1, t+1}=\rho e_{-1, t}+u_{-1, t+1} \\
e_{1, t+1}=\rho e_{1, t}+u_{1, t+1}
\end{array}\right.
$$

where the innovations $\left(u_{-1, t+1}, u_{1, t+1}\right)$ are drawn from a bivariate distribution such that $\operatorname{Var}\left(u_{-1, t+1}\right)=\operatorname{Var}\left(u_{1, t+1}\right)$ and $\operatorname{Corr}\left(u_{-1, t+1}, u_{1, t+1}\right)$ is not necessarily zero.

Let us consider the following decomposition: $u_{-1, t}=\zeta_{t}+\xi_{t}$ and $u_{1, t}=\zeta_{t}-\xi_{t}$, where $\zeta_{t}$ and $\xi_{t}$ are independent zero-mean transitory shocks. According to this decomposition, $\zeta_{t}$ is the component of the innovation to labor income that is common across locations. The remaining component, $\xi_{t}$, is purely location-specific and depends on where the person works. Then, $e_{-1, t}$ and $e_{1, t}$ can be written as

$$
\left\{\begin{array}{l}
e_{-1, t}=g_{t}+x_{t} \\
e_{1, t}=g_{t}-x_{t}
\end{array}\right.
$$

where $x_{t}$ and $g_{t}$ are independent $\mathrm{AR}(1)$ processes with a common persistence $\rho$ and innovations $\xi_{t}$ and $\zeta_{t}$, respectively. Let $\sigma_{x}^{2}=\left(1-\rho^{2}\right) \operatorname{Var}\left(x_{t}\right)$. The common component $g_{t}$ has no impact on mobility and the wage gap between movers and stayers. Specifically, given the flow utility, an individual's mobility decision is determined by local technology shock $z$ and the location-specific component $x$. Moreover, it can be seen that the component of labor income shocks that is not affected by individuals' locational choice (i.e., the component $g$ in equation (8)) does not affect the wage gap between movers and stayers. It is important to keep the latter point in mind when characterizing the mobility decision and evaluating the model quantitatively.

\subsection{Old workers}

We now provide the definition of the expected utility values associated with individuals' mobility decision. For the reasons explained earlier, we define the expected lifetime 
utility using the values of $x$ and $z$.

Let $U_{j}^{o}(z, x, \mu)$ denote the life-time utility of an old worker who worked in the previous period in location $j \in\{-1,1\}$. For an old worker who worked in the previous period in location $j$, the life-time utility of staying in the current location is given by

$$
S_{j}^{o}(z, x, \mu)=w_{j}(z, x, \mu)+\beta\left(1-\lambda^{o}\right) E U_{j}^{o}\left(z^{\prime}, x^{\prime}, \mu \mid z, x\right)
$$

where $\beta$ is the time-discount factor, $\lambda^{o}$ is the probability of retirement for an old workers, and $E$ denotes the conditional expectation and

$$
w_{j}(z, x, \mu)=\mu-j x+\frac{1-j}{2} z .
$$

If the old person moves to location $-j$ and works there for the current period, the life-time utility is

$$
M_{j}^{o}(z, x, \mu)=w_{-j}(z, x, \mu)-C(\mu, o)+\beta\left(1-\lambda^{o}\right) E U_{-j}^{o}\left(z^{\prime}, x^{\prime}, \mu \mid z, x\right) .
$$

Then, the maximized life-time utility of the old worker is given by

$$
U_{j}^{o}(z, x, \mu)=\max \left\{S_{j}^{o}(z, x, \mu), M_{j}^{o}(z, x, \mu)\right\}
$$

\subsection{Young workers}

Let $U_{j}^{y}(z, x, \mu)$ denote the life-time utility of a young worker who worked in the previous period in location $j \in\{-1,1\}$. For this person, the life-time utility of staying in the location is given by

$$
S_{j}^{y}(z, x, \mu)=w_{j}(z, x, \mu)+\beta \lambda^{y} E U_{j}^{o}\left(z^{\prime}, x^{\prime}, \mu \mid z, x\right)+\beta\left(1-\lambda^{y}\right) E U_{j}^{y}\left(z^{\prime}, x^{\prime}, \mu \mid z, x\right),
$$


where $\lambda^{y}$ is the probability that a young worker becomes old. For the young person, the expected value of moving to location $-j$ is given by

$$
\begin{gathered}
M_{j}^{y}(z, x, \mu)=w_{-j}(z, x, \mu)-C(\mu, y)+\beta \lambda^{y} E U_{-j}^{o}\left(z^{\prime}, x^{\prime}, \mu \mid z, x\right) \\
+\beta\left(1-\lambda^{y}\right) E U_{-j}^{y}\left(z^{\prime}, x^{\prime}, \mu \mid z, x\right) .
\end{gathered}
$$

Then, the maximized life-time utility of the young person is

$$
U_{j}^{y}(z, x, \mu)=\max \left\{S_{j}^{y}(z, x, \mu), M_{j}^{y}(z, x, \mu)\right\}
$$

\subsection{Population dynamics}

Let $\tau \in\{0,1,2, \cdots\}$ denote the number of periods a person has worked in their current location since his last move or birth. Suppose that, at the end of period $t$, there are $\phi_{j, t}(x, \mu, a, \tau)$ workers who have worked in their current location $j$ for $\tau$ periods and whose unobserved ability, age and current income shock are, respectively, $\mu, a$ and $x$. Given this measure, the number of people working (hereafter employment) in region $j$ is

$$
N_{j, t}=\sum_{\tau} \sum_{a} \sum_{\mu} \int \phi_{j, t}(x, \mu, a, \tau) d x .
$$

Let the total number of workers in the economy be normalized to 1, i.e., $N_{-1, t}+N_{1, t}=1$ for each $t$. For each quadruplet $(x, \mu, a, \tau)$, the number of workers after the realization of the idiosyncratic shocks at time $t$ is given by

$$
\psi_{j, t}(x, \mu, a, \tau)=\int \phi_{j, t-1}(\tilde{x}, \mu, a, \tau) \frac{\partial H(x \mid \tilde{x})}{\partial \tilde{x}} d \tilde{x}
$$

where $H$ denotes the conditional distribution function dictated by the AR(1) shock of $x$.

Now let $D_{j}$ denote the decision rule governing whether a worker in location $j$ stays 
in her current location or moves in period $t$ :

$$
D_{j, t}(x, \mu, a)= \begin{cases}1 & \text { if } S_{j}\left(z_{t}, x, \mu, a\right) \geq M_{j}\left(z_{t}, x, \mu, a\right) \\ 0 & \text { otherwise }\end{cases}
$$

where $z_{t}$ is the local technology shock at time $t$. Then, the number of workers moving from $j$ to $-j$ with $(x, \mu)$ at time $t$ is given by

$$
n_{-j, t}(x, \mu, a)=\sum_{\tau}\left(1-D_{j, t}(x, \mu, a)\right) \psi_{j, t}(x, \mu, a, \tau)
$$

The measure of young $(y)$ and old $(o)$ workers with $\tau=1$ is given by

$$
\left\{\begin{array}{l}
\phi_{j, t}(x, \mu, y, 1)=\left(1-\lambda^{y}\right) n_{j, t}(x, \mu, y) \\
\phi_{j, t}(x, \mu, o, 1)=\lambda^{y} n_{j, t}(x, \mu, y)+\left(1-\lambda^{o}\right) n_{j, t}(x, \mu, o)
\end{array}\right.
$$

while that of workers with $\tau>1$ is given by

$$
\left\{\begin{array}{l}
\phi_{j, t}(x, \mu, y, \tau)=\left(1-\lambda^{y}\right) D_{j, t}(x, \mu, y) \psi_{j, t}(x, \mu, y, \tau) \\
\phi_{j, t}(x, \mu, o, \tau)=\left(1-\lambda^{o}\right) D_{j, t}(x, \mu, o) \psi_{j, t}(x, \mu, o, \tau)+\lambda^{y} D_{j, t}(x, \mu, y) \psi_{j, t}(x, \mu, y, \tau)
\end{array}\right.
$$

It is assumed that the number of new workers entering each location is proportional to the number of current young stayers of the location:

$$
\phi_{j, t}(x, \mu, y, 0)=\frac{\lambda^{y}}{1-\lambda^{y}} D_{j, t}(x, \mu, y) \sum_{\tau>0} \psi_{j, t}(x, \mu, y, \tau)
$$

In the empirical implementation of the model, the duration of a unit period is one year. Accordingly, given how mobility and wage differences between movers and stayers were measured in Section 2, individuals with a tenure of up to five years are considered recent in-migrants. 


\subsection{What drives the mover-stayer wage gap?}

Clearly, because of stronger selection, a worker with a higher moving cost will have a higher wage at the destination. Another channel through which moving cost can affect the wage gap between movers and stayers is unobserved ability. Specifically, for a given level of mobility, one can obtain a substantial wage gap between movers and stayers by making workers of a certain ability level more or less mobile than the rest of the workers. Moreover, as shown in Lkhagvasuren (2014), one can obtain a substantial wage gap between movers and stayers by using a persistent location-specific shock even in the absence of costly mobility and unobserved ability. At the same time, more persistent shocks lowers mobility. So, despite the simplicity of the model, mobility and wages are related through these different channels. To determine whether these effects can generate the observed individual level wage-mobility relationship, we need to explore the model quantitatively while linking wages to both net and excess mobility.

\section{Empirical implementation}

Here the model is analyzed quantitatively using the key features of wages and mobility, including those documented in Section 2.

\subsection{Numerical method}

Solving for the mobility decision requires highly intensive computation due to the necessity to take into account heterogeneity in age, moving costs, local technology shocks and labor income shocks. In addition, when simulating the model, one must keep track of wages for each worker by their residential tenure, which refers to the number of years the person has been in the current location since his last move (or birth). Given that the mobility rate is measured at a five-year frequency, we need to record residential tenure for six different values of $\tau$. Moreover, simulating small 
geographic mobility requires a large number of agents and a very fine state space along the two types of the shocks.

Thus, both the solution and simulation amounts to a stochastic dynamic problem with a large state space. It should be emphasized that simulating the wage and mobility of these workers is not the main computational demand. Instead, keeping a record of residential history of each worker and using this information for every iteration of the calibration procedure (the minimum distance calibration) imposes the main computational demand. We combine discretization of state variables with value function iteration. This makes it easier to simulate a large number of heterogenous agents as the simulation of the economy and measurement of its moments amount to simple matrix operations. Given the nature of the problem, the discrete state space is highly desirable as it allows us to measure the wage gap more accurately using a stable discrete probability distribution of workers with a fixed domain.

The location-specific shock $x$ and the local technology shock $z$ are approximated by finite state Markov chains using the method of Rouwenhorst (1995). The latter method outperforms the other commonly used discretization methods for highly persistent AR(1) shocks such as those considered in Galindev and Lkhagvasuren (2010). Having fine discrete grids for both $x$ and $z$ is essential for generating mobility differences between the age groups and the observed wage gap. For this reason, the stochastic process for each of the two shocks is approximated by a 51-state Markov chain.

We simulate the model economy for $T=4000$ periods while keeping track of the distribution of heterogeneous agents over $(j, a, x, \tau)$. The first 400 periods are discarded, and $T$ is set large enough so that increasing it does not affect the moments. For the initial measures, $\mu_{j, 0}(a, x, \tau), j \in\{0,1\}$, we assume that all workers are distributed equally between the two sectors. Their within-region distribution over the mismatch shock $x$ is given by a binomial distribution with mean 0 and variance $\sigma_{x}^{2}$. 


\subsection{Calibration}

To enhance the computational tractability, the parameters are divided into two groups. Those in the first group, which is denoted by $\Theta_{\text {pre }}$, are pre-specified using the data and prior studies. Those in the second group, which is denoted by $\Theta_{m o m}$, are chosen specifically for the purpose of targeting certain data moments of the U.S. economy.

\section{Pre-specified parameters, $\Theta_{\text {pre }}$}

As stated in Section 3, the period length chosen for the numerical simulation is one

year. The time discount factor $\beta$ is set to $1 / 1.05$, which reflects an annual interest rate of 5 percent. Using the number of years in each age category, we set the aging probabilities to $\lambda^{y}=\lambda^{o}=1 / 15$. Wages of male household heads in the PSID from 1968-1997 are used to estimate the standard deviation of the mean log residual wage across individuals. These estimates are equal to 0.442 for high school graduates and 0.500 for college graduates.

Following Ciccone and Hall (1996), local productivity is measured using statespecific gross domestic product (GDP) released by the Bureau of Economic Analysis (BEA). Specifically, using the annual per-worker gross state product series from 1974 through 2004 constructed by Bauer and Lee (2005), the productivity of each census division is generated by taking the state employment share as the aggregation weight. Given these productivity series, local productivity is defined as the logarithm of perworker GDP in a given state relative to the logarithm of per-worker GDP for all U.S. states. For an average census division, the standard deviation of local productivity is 0.021 and the annual autocorrelation of the deviation of local productivity from its linear trend is 0.769. These numbers are used for $s_{z}$ and $\varrho$, respectively, and are summarized in the upper panel of Table 3. 


\section{Parameters chosen by targeting moments, $\Theta_{\text {mom }}$}

The moving costs are allowed to differ across age, education and unobserved ability. Specifically, we consider the following cost function:

$$
C(\mu, a)=c_{0}+c_{\mu} \mu+c_{\text {old }} d_{\text {old }},
$$

where $d_{o l d}$ is an indicator variable equal to one for old persons. According to equation (23), $c_{\text {old }}$ measures the age impact on moving costs. Notice that for each educational group, the moving cost is captured by three parameters. Thus, for each educational level, we need to choose the following five parameters: the persistence and spatial dispersion of labor income shocks, $\rho$ and $\sigma$, and the parameters of the cost function, $\left\{c_{0}, c_{\mu}, c_{\text {old }}\right\}$. These five parameters are chosen by targeting the following six data moments:

(c) gross mobility of young and old workers, $m^{y}$ and $m^{o}$;

(d) net mobility of young and old workers, $\delta^{y}$ and $\delta^{o}$; and

(b) wage differences between movers and stayers among young and old workers, $\gamma^{y}$ and $\gamma^{\circ}$.

Let $\Psi_{\text {data }}^{i}$ denote the $i$-th data moment where $i \in\{1,2, \ldots, 6\}$ and $\Psi_{\text {sim }}^{i}(\Theta)$ be the same

moment simulated under $\Theta=\left\{\Theta_{\text {pre }}, \Theta_{\text {mom }}\right\}$. Given $\Theta_{\text {pre }}$, the parameters $\Theta_{\text {mom }}=$ $\left\{\rho, \sigma, c_{0}, c_{\mu}, c_{o l d}\right\}$ are obtained by minimizing the following distance:

$$
\mathbf{L}(\Theta)=\sum_{i=1}^{6}\left(1-\frac{\Psi_{\text {sim }}^{i}(\Theta)}{\Psi_{\text {data }}^{i}}\right)^{2}
$$

For the remainder of the paper, the current calibration is referred to as the benchmark model. 
Table 3: Benchmark Parameterization under Parametric Cost

\begin{tabular}{cccl}
\hline parameters & high school & college & description \\
\hline \multicolumn{4}{c}{ Pre-specified parameters } \\
$\beta$ & $1 / 1.05$ & same & time discount factor \\
$\varrho$ & 0.769 & same & persistence of the regional shock \\
$\sigma_{z}$ & 0.013 & same & the standard deviation of the regional shock \\
$\sigma_{z} / \sqrt{1-\varrho^{2}}$ & 0.021 & same & the standard deviation of the regional shock \\
$s$ & 0.442 & 0.500 & dispersion of unobserved ability \\
& \multicolumn{3}{c}{ Key parameters } \\
$\rho$ & 0.9855 & 0.8201 & persistence of the labor income shock \\
$\sigma_{x}$ & 0.0144 & 0.0537 & the conditional dispersion of labor income shock \\
$\sigma_{x} / \sqrt{1-\rho^{2}}$ & 0.0851 & 0.0938 & spatial dispersion of labor income shock \\
$c_{o}$ & 0.2921 & 0.8288 & moving cost of a low ability young worker \\
$c_{\mu}$ & 0.2893 & 0.0536 & marginal cost of ability \\
$c_{\text {old }}$ & 0.2156 & 0.2465 & age impact on the moving cost \\
\hline
\end{tabular}

\subsection{Results}

The parameters of the benchmark model are displayed in Table 3 and the targeted data moments are presented in column $(i)$ of Table 4 while the associated simulated moments are summarized in column $(i i) .{ }^{10}$ The model is able to capture the key features of mobility and mover-stayer wage differences of the four different demographic groups. What is more reassuring is that although we target six moments using five parameters, the model performs remarkably well along many dimensions.

The values of $\sigma_{x}$ imply that the conditional standard deviation of the locationspecific labor income shock is higher for college graduate students than for high school graduates. The persistence of the idiosyncratic shocks are 0.986 and 0.820 for high school and college graduates respectively. Given the decomposition in equation (8) and the fact that each year, movers constitute a small fraction of the labor force, the

\footnotetext{
${ }^{10}$ In the current model, moving costs reflect both the direct and psychological costs of traveling long distances to take a job. The prediction that within each age-and-education group, workers with higher unobserved ability have higher moving costs might be linked to homeownership or spousal attachment to the current local market.
} 
Table 4: Data and Model Predictions

I. High school

gross mobility of young workers, $m^{y}$

gross mobility of old workers, $m^{o}$ net mobility of young workers, $\delta^{y}$ net mobility of old workers, $\delta^{o}$ share of net mobility of young workers, $v^{y}$ share of net mobility of old workers, $v^{y}$ mover-stayer wage gap among young workers, $\gamma^{y}$ mover-stayer wage gap among old workers, $\gamma^{o}$

\begin{tabular}{cccc}
$(i)$ & $($ ii $)$ & $($ iii $)$ & $($ iv $)$ \\
data & model & $C(y, \mu)$ & $C(o, \mu)$ \\
\hline 0.0530 & 0.0518 & 0.0501 & 0.0386 \\
0.0290 & 0.0302 & 0.0452 & 0.0317 \\
0.0080 & 0.0107 & 0.0108 & 0.0073 \\
0.0070 & 0.0065 & 0.0108 & 0.0065 \\
$15 \%$ & $21 \%$ & $22 \%$ & $19 \%$ \\
$24 \%$ & $22 \%$ & $24 \%$ & $21 \%$ \\
-0.0970 & -0.0972 & -0.0926 & -0.0505 \\
-0.0830 & -0.0826 & -0.1092 & -0.0733
\end{tabular}

II. College

gross mobility of young workers, $m^{y}$

gross mobility of old workers, $m^{o}$ net mobility of young workers, $\delta^{y}$ net mobility of old workers, $\delta^{o}$ share of net mobility of young workers, $v^{y}$ share of net mobility of old workers, $v^{y}$ mover-stayer wage gap among young workers, $\gamma^{y}$ mover-stayer wage gap among old workers, $\gamma^{o}$

\begin{tabular}{ccrr}
$(i)$ & $($ ii $)$ & $($ iii $)$ & $($ iv $)$ \\
data & model & $C(y, \mu)$ & $C(o, \mu)$ \\
\hline 0.1130 & 0.1142 & 0.1117 & 0.0764 \\
0.0590 & 0.0582 & 0.0916 & 0.0560 \\
0.0130 & 0.0142 & 0.0140 & 0.0101 \\
0.0100 & 0.0087 & 0.0121 & 0.0080 \\
$12 \%$ & $12 \%$ & $13 \%$ & $13 \%$ \\
$17 \%$ & $15 \%$ & $13 \%$ & $14 \%$ \\
0.0510 & 0.0533 & 0.0547 & 0.0775 \\
0.0810 & 0.0791 & 0.0610 & 0.0859
\end{tabular}


persistence of the $x$ shock is virtually the same as the persistence of the overall labor income shock. In the empirical literature of labor income processes, persistence of a labor income shock is quite high, in the range of 0.8 to 1. (e.g., Guvenen (2009)). So, the persistence parameters implied by the model are consistent with this evidence.

More importantly, moving costs increase with age. The difference between moving costs of young and old workers is approximately $20-25 \%$ of labor income. Below we demonstrate that this age difference in moving costs drives most of the age differences in mobility. For both groups, moving costs increase with ability, i.e. $c_{\mu}>0$. This means that, within each age and educational group, individuals with lower unobserved ability have lower moving costs and move more frequently than those with higher ability. In other words, movers tend to have less unobserved skills than observationally equivalent stayers.

In Section 2, it was shown that high-school-educated movers earn less than their non-migrant counterparts, while college-educated workers earn more compared with the college-educated non-movers. The quantitative results presented in Tables 3 and 4 offer an explanation for these data patterns. For high-school-educated workers, the mover-stayer wage gap is negative for two reasons. First, due to the lower moving costs of lower ability workers, low ability workers move more often. Second, as shown in Lkhagvasuren (2014), even when lower and higher ability workers have the same moving costs, the negative wage gap between movers and stayers may arise in the presence of a highly persistent location match shock.

For college-educated workers, low ability workers also have slightly lower moving costs. This small ability difference in moving costs may create a negative mover-stayer wage gap. However, this small effect is dominated by a positive selection effect of their more volatile location-match shock.

In Table 2, it was established that the negative mover-stayer wage gap of high school graduates shrinks with age while the positive mover-stayer wage gap of college-educated 
workers increases with age. For this seemingly different data pattern between the two educational group, the model offers a simple and unique explanation, namely that older workers have higher moving costs. Specifically, because of their higher moving costs, older workers only move when they have a much better wage draw at the destination. Therefore, the selection effect along the income shock dimension is higher among older workers making the wages of older movers larger relative to those of younger movers.

\section{Counterfactual experiments}

In this section, we consider numerical experiments to analyze how the elements of the model affect mobility of different age groups. By means of simulating the model under different parameter values and restrictions, these experiments also show how sensitive the simulated moments are to the selected parameters and how the key elements of the model are important for understanding both mobility and wages.

First we simulate the model while removing the age impact on the moving cost. In other words, we re-simulate the model while setting $c_{a}$ to zero in equation (23). This helps us quantify the fraction of the mobility gap that is explained by moving cost differences between the age groups. The higher moving costs among old workers explain $69.4 \%(=100 \% \times(0.0452-0.0302) /(0.0518-0.0302))$ of the age gap in mobility among high school graduates. For college graduates, the number is also high, at $59.6 \%(=100 \% \times(0.0916-0.0582) /(0.1142-0.0582))$. So, according to this experiment, the higher moving costs among old workers explain approximately two thirds of the mobility gap among young and old workers.

Another main finding is that as moving costs of old people are lowered, the wages of movers relative to those of stayers decrease sharply. For example, for high school graduates, the wage of in-migrants relative to that of stayers decreases from $-8.3 \%$ to $-10.9 \%$. For college graduates it decreases from $7.9 \%$ to $6.1 \%$. These illustrate our 
key message that higher moving cost among older workers are more important for understanding the wage-mobility relationship among different demographic groups.

This experiment also illustrates an interesting dynamic effect that lower moving costs among older workers reduce mobility of younger workers. For example, according to Table 4, when we reduce the moving cost among older workers, mobility among younger workers go down from $5.2 \%$ to $5.0 \%$. Among college graduates, mobility drops from $11.4 \%$ to $11.2 \%$. The effect is lower for the college graduates, perhaps because the persistence of the income shock is slightly lower for them and therefore the current shocks do not have a smaller impact on the income accrued in the future when they become old. Nevertheless, the reason behind this drop is that when the future cost is lower, individuals are not that sensitive to today's income shocks. Indeed, we observe that, with a lower future cost, the selection effect on the young workers become stronger. When there is a lower cost in the future, young workers move only when the shock at the destination is really good, which, in turn, results in a higher mover-stayer wage gap.

Next we simulate the model while imposing the moving cost of old workers on the young workers. Using this exercise, we examine how the higher moving costs affect young workers today. The main results are summarized in Table 4, in the column denoted by $C^{o}(\mu)$. With higher moving costs, the mobility of the young workers decreases.

For high school graduates, $61 \%(=100 \% \times(0.0518-0.0386) /(0.0518-0.0302))$ of the mobility difference is explained by the moving cost. However, for college graduates, the number is even higher, $68 \%(=100 \% \times(11.42-7.64) /(11.42-5.82))$. At the same time, the movers perform better than the benchmark case when we compare their wages with those of stayers. This is because the selection effect generated by the moving cost. 


\section{Conclusions}

We extend the standard Roy (1951) model of locational choice into a dynamic stochastic setting while allowing for both net and gross mobility. We analyze the model using key patterns of micro data on mobility and wages, including new evidence on the variability of mobility across regions and on the wage gap between movers and stayers. According to this model, a higher moving cost among older workers is the main factor for observed mobility differences between young and old workers. The model is also able to generate a pattern that, when compared with otherwise similar incumbent workers, older movers perform better than young movers.

We show that allowing for the quantitative differences in two key elements of a multisector model, the spatial dispersion of labor income and moving costs, one can generate a quite rich pattern for the relationship between mobility and wages. Put differently, seemingly different patterns of mobility and wages may not necessarily imply different underlying mechanisms in a multi-sector model. Instead, these different patterns might share the same mechanism but with quantitative differences in selected key parameters. Moreover, incorrect measurement of the basic parameters of a multi-sector model could lead to important oversights regarding the underlying income processes.

The results in this paper suggest that introducing directed mobility in the presence of persistent location-specific productivity into an otherwise standard multi-location model could greatly improve the model's predictions and thus provide a flexible framework within which important quantitative issues can be addressed. For example, our

finding that mobility differences among workers of different ages are mainly driven by differences in moving costs points to the policy of subsidizing moving costs, especially 
among older workers. ${ }^{11}$ Put differently, the model results suggest that subsidizing the moving cost could be a more efficient way to raise labor income among an older labor force than other policy instruments, such as training those workers locally.

In this paper, moving costs are specific to a demographic group. Clearly, within a demographic group, moving costs are heterogeneous. Moreover, the moving cost of a particular individual may change over time. For example, an older worker is more likely to be a homeowner and housing tenure may change by regional mobility. Thus, it would be of interest to repeat the analysis in this paper in the context of the housing market. This may allow one to measure the extent to which homeownership lowers labor income, especially among older workers. ${ }^{12}$ Moreover, analyzing the model using cross-country data and shorter distance mobility may provide insight into the role of labor mobility in cross-country gaps in overall labor income. Future research should look at these important variables. Nevertheless, this study can be viewed as an important step toward understanding how wage and mobility are related at the individual level across different demographic groups.

\section{Appendix}

McLaughlin and Bils (2001) point out that to measure the wage of movers, one needs a large data set, as movers are a small fraction of the population. To see this, let there be $J$ regions in the economy. Let $N(J)$ be the average number of people residing in a region and let $m(J)$ denote the overall mobility rate associated with these $J$ regions. Clearly, the variance of the measured wage differences between movers and

\footnotetext{
${ }^{11}$ In the U.S., the moving cost subsidies typically work through income taxes. For example, according to the current Federal Income Tax code of the U.S., individuals deduct their moving expenses from their annual income tax return. Also, an individual's eligibility for unemployment benefits critically depends on the location (state) tenure. This eligibility criteria also raises the moving cost. For theoretical studies on how the moving cost, the key policy variable in a multi-sector model, affects the aggregate labor market, see, for example, Lucas and Prescott (1974) and Lee and Wolpin (2006).

${ }^{12}$ For studies on the impact of homeownership on the labor market, see, for example, Blanchflower and Oswald (2013); Munch, Rosholm and Svarer (2006); Coulson and Fisher (2009).
} 
stayers decreases with the average number of in-migrants within a region, $N(J) m(J)$. Therefore, in order to reduce the impact of measurement error, one has to proceed with larger sub-national units, i.e., a larger $N(J)$. However, it is well known that migration decreases with distance, meaning that the mobility rate, $m(J)$, decreases as $J$ goes down (Greenwood, 1997). Therefore, one has to use a large data set while maintaining a balance between the number of regions, $J$, and the number of movers, $m(J)$.

Another key data moment that requires a large number of observations is the volatility of mobility across regions. Specifically, having a lower number of movers within each region makes it hard to construct a meaningful empirical pattern of regional level variation in mobility and net mobility for each age and educational group. For these considerations, we proceed with the U.S. census data while taking the nine census divisions as the main basic geographic units. Finally, it should be mentioned that, according to Blanchard and Katz (1992), the census divisions are relatively homogeneous and thus provide a natural way to pool U.S. states.

\section{References}

Bauer, Paul and Lee, Yoonsoo. (2005). 'Labor Productivity Growth Across States', Federal Reserve Bank of Cleveland Policy Discussion Paper 16.

Bayer, Christian and Juessen, Falko. (2012). 'On the Dynamics of Interstate Migration: Migration Costs and Self-Selection', Review of Economic Dynamics $15(3), 377-401$.

Blanchard, Olivier and Katz, Lawrence. (1992). 'Regional Evolutions', Brookings Papers on Economic Activity 23(1), 1-61.

Blanchflower, David G. and Oswald, Andrew J. (2013), Does High HomeOwnership Impair the Labor Market?, Discussion Paper 7640, IZA.

Borjas, George J., Bronars, Stephen G. and Trejo, Stephen J. (1992a). 'Assimilation and the Earnings of Young Internal Migrants', Review of Economics and Statistics 74(1), 170-175.

Borjas, George J., Bronars, Stephen G. and Trejo, Stephen J. (1992b). 'Self- 
Selection and Internal Migration in the United States', Journal of Urban Economics 32(2), 159-185.

Ciccone, Antonio and Hall, Robert. (1996). 'Productivity and the Density of Economic Activity', American Economic Review 86(1), 54-70.

Coen-Pirani, Daniele. (2010). 'Understanding Gross Worker Flows Across US States', Journal of Monetary Economics 57(7), 769-784.

Coulson, N. Edward and Fisher, Lynn M. (2009). 'Housing tenure and labor market impacts: The search goes on', Journal of Urban Economics 65(3), 252264.

Dahl, Gordon. (2002). 'Mobility and the Return to Education: Testing a Roy Model with Multiple Markets', Econometrica 70(6), 2367-2420.

Davis, Steven J. and Haltiwanger, John. (1992). 'Gross Job Creation, Gross Job Destruction, and Employment Reallocation', The Quarterly Journal of Economics 107(3), 819-863.

Galindev, Ragchaasuren and Lkhagvasuren, Damba. (2010). 'Discretization of Highly Persistent Correlated AR(1) Shocks', Journal of Economic Dynamics and Control 34(7), 1260-1276.

Gertler, Mark. (1999). 'Government Debt and Social Security in a Life-cycle Economy', Carnegie-Rochester Conference Series on Public Policy 50, 61-110.

Grafenhofer, Dominik, Jaag, Christian, Keuschnigg, Christian and Keuschnigg, Mirela. (2007). 'Economic Ageing and Demographic Change', Vienna Yearbook of Population Research 5(1), 133-165.

Grant, Kenneth and Vanderkamp, John. (1980). 'The Effects of Migration on Income: A Micro Study with Canadian Data 1965-71', Canadian Journal of Economics 13, 381-406.

Greenwood, Michael J. (1997), Internal Migration in Developed Countries, in Mark R. Rosenzweig and Oded Stark., eds, 'Handbook of Population and Family Economics Vol. 1B', North Holland, New York.

Guvenen, Fatih. (2009). 'An Empirical Investigation of Labor Income Processes', Review of Economic Dynamics 12, 58-79.

Heckman, James J. and Taber, Christopher. (2008), Roy Model, in Steven N. Durlauf and Lawrence E. Blume., eds, 'The New Palgrave Dictionary of Economics, Second Edition', Palgrave Macmillan. 
Hock, Heinrich and Weil, David. (2012). 'On the Dynamics of the Age Structure, Dependency, and Consumption', Journal of Population Economics 25(3), 10191043.

Kennan, John and Walker, James R. (2011). 'The Effect of Expected Income on Individual Migration Decisions', Econometrica 76(1), 211-251.

Krieg, Randall G. (1997). 'Occupational Change, Employer Change, Internal Migration, and Earnings', Regional Science and Urban Economics 27, 1-15.

Lee, Donghoon and Wolpin, Kenneth I. (2006). 'Intersectoral Labor Mobility and the Growth of the Service Sector', Econometrica 74, 1-46.

Lkhagvasuren, Damba. (2012). 'Big Locational Unemployment Differences Despite High Labor Mobility', Journal of Monetary Economics 59(8), 798-814.

Lkhagvasuren, Damba. (2014). 'Education, Mobility and the College Wage Premium', European Economic Review 67, 159-173.

Lucas, Jr., Robert E. and Prescott, Edward C. (1974). 'Equilibrium Search and Unemployment', Journal of Economic Theory 7, 188-209.

Machin, Stephen, Pelkonen, Panu and Salvanes, Kjell G. (2012). 'Education and Mobility', Journal of the European Economic Association 10(2), 1-15.

Malamud, Ofer and Wozniak, Abigail K. (2012). 'The Impact of College Education on Geographic Mobility', Journal of Human Resources 47(4), 913-950.

McLaughlin, Kenneth and Bils, Mark. (2001). 'Interindustry Mobility and the Cyclical Upgrading of Labor', Journal of Labor Economics 19, 94-135.

Moscarini, Giuseppe. (2001). 'Excess Worker Reallocation', The Review of Economic Studies 68, 593-612.

Munch, Jakob Roland, Rosholm, Michael and Svarer, Michael. (2006). 'Are home owners really more unemployed?', Economic Journal 116(514), 991-1013.

Rouwenhorst, Geert K. (1995), Asset Pricing Implications of Equilibrium Business Cycle Models, in Thomas Cooley., ed., 'Frontiers of Business Cycle Research', Princeton University Press, Princeton, pp. 294-330.

Roy, A. D. (1951). 'Some Thoughts on the Distribution of Earnings', Oxford Economic Papers 3, 135-146.

Ruggles, Steven J., Alexander, Trent, Genadek, Katie, Goeken, Ronald, Schroeder, Matthew B. and Sobek, Matthew. (2010), Integrated Public Use Microdata Series: Version 5.0 [Machine-readable database]. Minneapolis: Univer- 
sity of Minnesota.

Topel, Robert H. (1986). 'Local Labor Markets', Journal of Political Economy 94(3), S111-S143. 